ORIGINAL ARTICLE

\title{
Health, lifestyle, and quality of life for young adults born very preterm
}

\section{R W I Cooke}

Correspondence to:

Prof. R W I Cooke,

Neonatal Unit, Liverpool

Women's Hospital, Crown

Street, Liverpool L8 7SS,

UK; mc19@liv.ac.uk

Accepted 11 July 2003
Background: Children born very preterm and able to attend mainstream schools have been shown to have a high prevalence of behavioural, minor motor, and learning difficulties. It is not clear whether these problems persist into adulthood, impacting on lifestyle and quality of life.

Methods: A previously studied cohort of very low birth weight infants born between 1980 and 1983, together with term classmate controls, were assessed at age 19-22 years using a postal questionnaire. The questionnaire included the SF-36 to assess quality of life, a social activities scale, a lifestyle questionnaire, the Hospital Anxiety and Depression Scale, and questions on current height, weight, health, family structure, and education and occupation.

Results: Of the 138 preterm and 163 term controls in the cohort, 79 preterm and 71 term returned questionnaires. Quality of life was assessed as similar on six of eight domains of the SF-36. Social activities were also similar. Preterms drank less alcohol, used fewer illicit drugs, but smoked as often. Rates for sexual intercourse were similar, although preterms had more children. Preterms were shorter than controls and were less satisfied with their appearance. They were more likely to use a regular prescription medicine. Fewer were or had been in higher education, and some remained unemployed.

Conclusion: The problems experienced by very preterm infants at school appear to influence lifestyle and health, but not perceived quality of life in early adulthood.
$M$ odern neonatal intensive care has greatly reduced the mortality of very low birth weight (VLBW) infants, although it is recognised that $10-15 \%$ of survivors will have a major neurodisability. ${ }^{1}$ Those attending mainstream schools, while free of major problems, have been noted to have a high prevalence of minor motor, behavioural, and learning difficulties often associated with visual perception disorder. ${ }^{2}$ These problems which first present at junior school, do seem to persist into adolescence, when they are also associated with difficulties in forming relationships and in social functioning. ${ }^{3}$ A cohort of VLBW infants born in Liverpool, UK in 1980-83 has been followed at school together with term controls at 6 and 12 years. ${ }^{3-9}$ The present study aimed to investigate the impact of the difficulties observed at school on their self perceived health and quality of life in early adult life. Early studies of adults born at VLBW were very optimistic about adult outcomes, ${ }^{10}$ but more recent reports from Europe ${ }^{11-15}$ and the USA ${ }^{16}$ have described more problems. All such very long term follow up studies suffer from biases introduced by initial cohort selection, and by attrition. Most are hospital based cohorts, and many have been selected by birth weight rather than gestational age, which increases the proportion of growth restricted infants included. Subjects lost to follow up may be different in many respects such as intelligence, disabilities, and socioeconomic status. ${ }^{17}{ }^{18}$ Studies usually try to compare variables describing neonatal or early childhood characteristics in the followed up group and those lost to follow up, but this cannot guarantee comparability. Postal questionnaire follow up rather than face-to-face examination also results in further losses.

In view of the difficulties seen in this cohort in early adolescence, it was anticipated that they would show poorer educational attainment and employment status, and less satisfactory personal relationships and satisfaction with their quality of life in early adulthood. Despite the difficulties in follow up it was thought important to ascertain the current status of those in the cohort that could be traced.

\section{METHODS}

The study cohort originally comprised two groups of very low birth weight preterm infants born in 1980-81 and 1982-83 at Liverpool Maternity Hospital, Liverpool together with age, sex, and first language matched term classmate controls. Only those able to attend a mainstream school were included. The first group were studied at school at 6 and 8 years, the second at 6 years, and both together at 12 years. When a control did not enter the same secondary school as the preterm subject, a further control was sought and both controls followed. The results of the studies on this combined cohort have been extensively published previously. ${ }^{3-9}$

All term (T) and preterm (PT) subjects in the cohort were contacted by post at their last known address. A letter explaining the study and inviting them to take part was sent, with a single reminder two months later to non-responders. Those returning a prepaid card were sent the questionnaire. Reminder letters were sent to those not returning the questionnaire within a month. The questionnaire was identified only by a study code, and anonymity promised.

The questionnaire comprised the Short Form 36 Health Survey (SF-36), ${ }^{19}$ a Social Activities Scale, the Hospital Anxiety and Depression Scale (HADS), ${ }^{20}$ and questions on alcohol and drug use, sexual activity, relationships, pregnancy, involvement with the police, current height and weight, self-image, medications, academic achievements, household structure, and employment status. The draft

Abbreviations: HADS, Hospital Anxiety and Depression Scale; IQR, interquartile range; $\mathrm{OR}$, odds ratio; $\mathrm{PT}$, preterm; $\mathrm{T}$, term; VLBW, very low birth weight 
questionnaire was piloted with three young adults and three parents, and minor modifications made. All responses were through tick boxes, except for a free-text section for medications used and current occupation. It consisted of 13 pages, and took about 10-15 minutes to complete.

The returned questionnaires were transcribed to a database, and standardised values for the eight domains of the SF-36 computed. The SF-36 is a short 36 item questionnaire which measures eight multi-item dimensions: physical functioning (10 items), role limitation due to physical problems (4 items), role limitation due to emotional problems (3 items), social functioning (2 items), mental health ( 5 items), energy and vitality ( 4 items), pain ( 2 items), and general health perception ( 5 items). For each dimension item scores are coded, summed, and transformed on to a scale from 0 (worst state) to 100 (best possible state). The SF36 has undergone validity testing in the UK which has included examination of the content, criterion, and construct validity of the instrument. ${ }^{21}$

The Social Activities Scale listed nine activities involving others, and asked whether in the past three months they had engaged in each of these once a week, once a month, once or twice, or not at all.

The HADS is a brief assessment of anxiety and depression, consisting of 14 items divided into two subscales for anxiety and depression, in which the subject rates each item on a four point scale. Scores of 11 and more are considered to indicate definite cases. It has been extensively validated in the UK. The remaining questions on the questionnaire were essentially statements of fact.

Returned questionnaires were checked against a mailing list before being anonymised by removal of the front sheet. This allowed checking of returns against non-returns on a database of test data collected in schools at 12 years, to examine for selection bias (table 1).

\section{RESULTS}

The original cohort consisted of 301 subjects (138 preterm and 163 term controls). A total of 185 replies were received to the letter inviting participation, of which two were refusals. Forty letters were returned by the post office as "not known at this address"; 76 did not reply after two attempts to contact them; 183 questionnaires were sent out and 150 $(82 \%)$ were returned. To examine for bias among those who returned questionnaires, motor impairment scores, intelligence quotients, height and head circumferences at 12 years were examined together with sex and preterm status (table 1). Twelve year variables did not differ significantly, but females and those born preterm were significantly more likely to return the questionnaire. The mean (SD) age at completion of the questionnaire was 20 (1.1) years for both $\mathrm{T}$ and PT subjects.

Table 1 Characteristics of subjects who did or did not return a questionnaire

\begin{tabular}{llll}
\hline & No questionnaire (151) & Questionnaire (150) & $\mathbf{p}$ \\
\hline TOMI-12 & $2(1-4.375)$ & $2(1-4)$ & 0.950 \\
IQ-12 & $92(18)$ & $96(17)$ & 0.062 \\
Height-12 & $148(8.7)$ & $147(8.2)$ & 0.349 \\
OFC-12 & $54.0(1.7)$ & $53.8(1.7)$ & 0.493 \\
Male & $87(57.6 \%)$ & $65(43.3 \%)$ & 0.018 \\
Preterm & $60(39.7 \%)$ & $79(52.7 \%)$ & 0.014 \\
\hline
\end{tabular}

TOML-12, score on test of motor impairment at age 12 years. $I Q-12$, score on WISC-3 intelligence test at 12 years. Height-12, mean height in $\mathrm{cm}$ (SD) at 12 years.

OFC-12, mean occipitofrontal head circumference in $\mathrm{cm}(S D)$ at 12 years.
The scores on the eight domains of the SF-36 were similar to published UK age and sex related norms ${ }^{19}$ (table 2). Females scored lower in all domains, but lowest in role limitation due to emotional problems, mental health, and energy and vitality domains. The only significant differences between $\mathrm{T}$ and PT were a lower physical functioning score (male and all) and a lower general health perception score (male).

Both groups showed involvement in a wide range of social activities (table 3 ). The only significant difference was that the PT group visited a pub or club less often (OR $0.27,95 \%$ CI 0.10 to 0.72 ). This is consistent with the lower frequency of alcohol consumption reported by this group (OR $0.21,95 \%$ CI 0.06 to 0.75 ).

Scores for anxiety and depression are shown in table 4 as medians (IQR), and were similar for PT and T. Scores of 11 or more indicate a clinically significant level of illness; 16 PT and $13 \mathrm{~T}$ showed a significant anxiety state, but only one PT had clinical depression. Females were significantly more likely to have an anxiety state $(\mathrm{p}=0.02)$.

Table 5 shows reported lifestyles, relationships, and involvement with police. PT females and PT overall consumed alcohol significantly less frequently (OR $0.21,95 \%$ CI 0.06 to 0.75). PT men and women also smoked cannabis less frequently (OR $0.31,95 \%$ CI 0.15 to 0.64 ) and rarely used Ecstasy (OR $0.11,95 \%$ CI 0.02 to 0.48 ). Cigarette smoking habits were similar between the groups. There were no significant differences in the proportions of each group that had experienced sexual intercourse or who had sex at least once a week during the previous three months. Similar numbers had been in an intimate relationship previously or were in such a relationship at present. Pregnancy rates were similar, but more of the PT women were living with their children. There were no differences in rates of involvement with the police between the groups.

Significant differences were seen between the T and PT in current mean heights and weights (table 6). Mean height for PT males was $4 \mathrm{~cm}$ shorter than $\mathrm{T}$ and mean weight $8.1 \mathrm{~kg}$ lighter. Mean height for PT females was $8 \mathrm{~cm}$ shorter than T. PT females expressed the wish to be taller twice as often as $\mathrm{T}$ females (OR 3.4, 95\% CI 1.40 to 8.37 ), and were significantly less likely to see themselves as attractive to others (OR 0.05, 95\% CI 0.01 to 0.41 ) (table 7). PT males also saw themselves as less attractive.

Twenty PT and $12 \mathrm{~T}$ were taking a regular prescribed medication, most commonly for asthma (12 PT, 4T).

PT were more likely to be still living at home with parents (OR 2.52, 95\% CI 1.10 to 5.37), and less likely to be living away from home with their peers, particularly if they were female (OR 0.05, 95\% CI 0.01 to 0.41) (table 8).

PT left school significantly earlier at 16.4 (1.1) years compared with $\mathrm{T}$ at 17.1 ( 1.1$)$ years, $(\mathrm{p}<0.001)$.

Academic qualifications achieved to date were significantly lower for the PT, with significantly more further education qualifications (OR 4.11, 95\% CI 2.01 to 8.36) and fewer university degrees (OR $0.21,95 \%$ CI 0.11 to 0.44 ) (table 8 ). More PT were in paid work (OR 2.01, 95\% CI 1.07 to 3.94 ) and fewer were full time students (OR 0.28 , 95\% CI 0.14 to 0.58 ) (table 8).

\section{DISCUSSION}

Contrary to expectations, the PT group reported similar quality of life on all but two domains on the SF-36: physical functioning and general health perception. This cohort excluded those with major neurodisability, but it was noted that the PT received prescribed medications more often than $\mathrm{T}(25 \% v 17 \%)$, especially for asthma $(15 \% v 6 \%, \mathrm{p}=0.06)$. In some studies poor growth has been classified as a chronic disorder. ${ }^{16}$ In this cohort, poor growth was noted at 12 years 
Table 2 Scores on the eight domains of the SF-36 questionnaire, by sex and gestational age at birth

\begin{tabular}{|c|c|c|c|c|c|c|}
\hline \multirow[b]{2}{*}{ Domain } & \multicolumn{2}{|l|}{ Male } & \multicolumn{2}{|l|}{ Female } & \multicolumn{2}{|l|}{ All } \\
\hline & Preterm & Term & Preterm & Term & Preterm & Term \\
\hline $\begin{array}{l}\text { Physical functioning } \\
\text { Role limit physical } \\
\text { Role limit emotional } \\
\text { Social functioning } \\
\text { Mental health } \\
\text { Energy and vitality } \\
\text { Pain } \\
\text { General health perception }\end{array}$ & $\begin{array}{l}94.4(8.8)^{*} \\
87.929 .3) \\
88.6(24.2) \\
92.4(20.3) \\
77.7(15.6) \\
68.6(17.9) \\
83.5(19.5) \\
70.9(22.8)^{*}\end{array}$ & $\begin{array}{l}98.0(5.3) \\
91.7(23.1) \\
86.7(29.8) \\
88.1(23.7) \\
75.6(21.0) \\
65.3(20.8) \\
87.8(19.0) \\
81.7(15.6)\end{array}$ & $\begin{array}{l}89.0(17.1) \\
86.4(31.2) \\
74.2(36.6) \\
82.3(25.4) \\
64.4(21.0) \\
54.2(23.3) \\
80.8(25.8) \\
69.9(23.9)\end{array}$ & $\begin{array}{l}93.4(12.1) \\
88.4(28.6) \\
67.5(43.1) \\
84.8(20.5) \\
66.9(20.7) \\
54.6(22.9) \\
84.8(16.6) \\
66.7(21.4)\end{array}$ & $\begin{array}{l}91.4(14.3)^{*} \\
87.0(30.2) \\
80.6(32.3) \\
86.8(23.7) \\
70.3(19.9) \\
60.6(22.2) \\
82.0(23.2) \\
70.3(23.3)\end{array}$ & $\begin{array}{l}95.4(10.0) \\
89.8(26.2) \\
75.6(39.0) \\
86.2(21.8) \\
70.6(21.1) \\
59.2(22.5) \\
86.1(17.6) \\
73.0(20.5)\end{array}$ \\
\hline
\end{tabular}

\begin{tabular}{|c|c|c|c|}
\hline & Preterm (79) & Term (71) & OR $(95 \% \mathrm{Cl})$ \\
\hline Visited family or friends & $69(84 \%)$ & $68(96)$ & $0.30(0.08$ to 1.10$)$ \\
\hline Aftended church or other place of worship & 11 (14) & $8(11)$ & 1.27 (0.48 to 3.37$)$ \\
\hline Aftended a group, club, or association & $27(34)$ & 27 (38) & 0.85 (0.43 to 1.65$)$ \\
\hline Gone to pub, club, or disco & $59(75)$ & $65(92)$ ** & 0.27 (0.10 to 0.72 ) \\
\hline Day trip or outing & $32(41)$ & $40(56)$ & $0.59(0.31$ to 1.12$)$ \\
\hline Gone to sports event & $22(28)$ & $18(25)$ & $1.14(0.55$ to 2.35$)$ \\
\hline Gone to theatre or cinema, concert, gig & $35(44)$ & $40(56)$ & $0.62(0.32$ to 1.18$)$ \\
\hline Family or friends visited you at home & $57(72)$ & $56(79)$ & 0.69 (0.33 to 1.47$)$ \\
\hline Short break or holiday & $44(56)$ & $47(66)$ & 0.64 (0.33 to 1.24$)$ \\
\hline
\end{tabular}

to be common in the PT, and associated with lower IQ scores and educational attainment. ${ }^{4}$ The short stature appears to have persisted as predicted, particularly in the women. The PT men are significantly lighter, although there are no differences in body mass index, or the number who were clinically obese or overweight for either sex. The short stature in many of the PT women was associated with a significantly higher proportion of them wishing that they were taller $(61 \%$ $v 32 \%, \mathrm{p}<0.01)$ and many fewer seeing themselves as more attractive than average to others $(2 \% v 32 \%, \mathrm{p}<0.001)$. PT males also were more likely to rate themselves as less attractive than average to others.

There appeared to be high rates of psychological problems, particularly among women, as identified by the low scores on role limitation due to emotional problems, mental health, and energy/vitality domains of the SF-36, and high scores on the HADS, although they were no more prevalent in PT than $\mathrm{T}$ (anxiety disorder 25\% $v 23 \%$ ). Clinically significant depression was only reported once, although several subjects who had high anxiety scores wrote on their questionnaires that they felt depressed. These rates for psychological disorders are similar to those previously reported in this age group, and in PT. ${ }^{16}$ When this cohort were examined using the Child and Adolescent Psychiatric Assessment at 12 years, anxiety was significantly more prevalent in PT $(8 \% \vee 1 \%$, $\mathrm{p}<0.01$ ) and clinical depression was rare. ${ }^{3}$ Overall psychological problems (mostly attention deficit and anxiety) were present in $28 \%$ PT at 12 years ( $10 \%$ term controls, p $<0.001$ ) which appears to reflect their present psychological status. The apparent increase in the frequency of anxiety in $\mathrm{T}$ adults may simply relate to leaving home and pressures of university life, to which the PT are less frequently exposed.

At 12 years the PT showed more difficulties in relating to others; in particular they had fewer friends, were more often bullied, and were more likely to make inappropriate relationships with other children and adults. ${ }^{3}$ This does not seem to have been a continuing problem as adults. The range of social activities undertaken was very similar in both groups, and the proportion reporting a serious relationship ever or at present was the same. The only social activity reported more frequently in $\mathrm{T}$ was visiting a pub, which correlates with the higher frequency of alcohol consumption observed. Cigarette smoking was higher in females and PT but not significantly so. Illegal drug use (cannabis, Ecstasy, heroin) was significantly more common in the $\mathrm{T}$ which accords with findings in a recent US study, although only in women. It seems that the PT are less prone to risk taking, possibly because more of them are at home, or because their parents are more protective. In this cohort PT adults were significantly more likely to be living at home with parents. PT girls were also less likely to be living away from home with their peers, possibly reflecting the fact that fewer were at university.

Similar proportions of both groups and either sex had experienced sexual intercourse, and about half of those reported intercourse at least once a week over the previous three months. Two $\mathrm{T}$ males reported active homosexual relationships, although this was not specifically enquired about on the questionnaire. Pregnancy rates were low

Table 4 Scores for anxiety and depression on the hospital anxiety and depression scale

\begin{tabular}{llrlr}
\hline & Preterm & $\geqslant 11$ & Term & $\geqslant 11$ \\
\hline Male & & & & \\
$\quad$ Anxiety & $5(2-8)$ & 4 & $4(3-7)$ & 3 \\
$\quad$ Depression & $2(1-3)$ & 0 & $2(1-4.25)$ & 0 \\
Female & & & $7(3-10.5)$ & 10 \\
$\quad$ Anxiety & $7(4-12.5)$ & 12 & $7(1-5.5)$ & 0 \\
$\quad$ Depression & $3(1-5)$ & 1 & $2(1-5)$ & \\
All & & & & \\
$\quad$ Anxiety & $6(3-10)$ & 16 & $5(3-10)$ & 13 \\
$\quad$ Depression & $2(1-4)$ & 1 & $2(1-5)$ & 0 \\
\hline
\end{tabular}




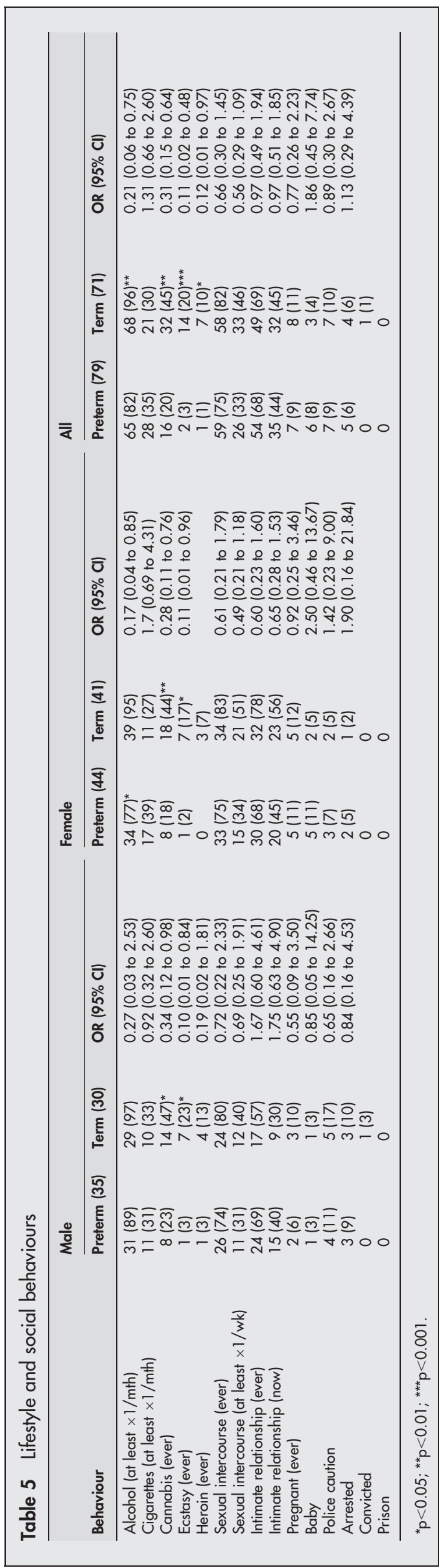

Table 6 Present height weight and body mass index

\begin{tabular}{|c|c|c|c|c|}
\hline & \multicolumn{2}{|l|}{ Male } & \multicolumn{2}{|l|}{ Female } \\
\hline & Preterm & Term & Preterm & Term \\
\hline Height, cm (SD) & $172(6.5)^{*}$ & $176(7.6)$ & $156(6.1)^{* * *}$ & $164(5.6)$ \\
\hline Weight, kg (SD) & $71.3(14.1)^{*}$ & * $79.4(15.9)$ & 9) 59.8 (15.5) & ) 62.7 (12.6) \\
\hline Body mass index & $x 24.0(4.6)$ & $25.5(5.3)$ & $24.4(6.1)$ & $23.4(4.3)$ \\
\hline
\end{tabular}

compared with the USA (for males this refers to pregnancy in a partner), and were similar in PT and T. The PT women had more births and all were still living with their children. This may indicate a greater vulnerability, but possibly more likely a life choice related to poor education or work prospects. A US study has shown lower intercourse, pregnancy, and birth rates in PT women. That cohort did contain adults with significant neurodevelopmental disorders, although the absence of differences between PT and T males suggests that this may not be an adequate explanation.

Contacts with the police were not uncommon, and mainly involved cautions and arrests; there was only one conviction and no imprisonments. It is likely that most of these contacts concerned alcohol and drugs offences. No differences between groups were seen. This picture is very different from the USA where up to $25 \%$ of males had been imprisoned by the age of 20, and involvement with police was less common in the PT males. ${ }^{16}$ This reflects different attitudes to policing and social differences.

As expected, academic achievements among the PT were less than the $\mathrm{T}$, although as many in each group had progressed beyond secondary education. More PT had vocational qualifications $(54 \% v 23 \%, \mathrm{p}<0.001)$ and fewer were at university or had completed a degree (23\% v 58\%, $\mathrm{p}<0.001)$ ). Unemployment rates were low overall, but higher in the PT; $81 \%$ PT and 93\% T were in paid work, work training or were full time students $(p=0.05)$. The difference is explained by women at home caring for children and unemployed men in the PT group.

This study has a number of limitations. The relatively small number of subjects was due to the constraints of using an established cohort which could not be extended for this study, and the loss of $50 \%$ of the cohort due to failure to trace them; $57 \%$ of the PT and $44 \%$ of the $\mathrm{T}$ returned a postal questionnaire, compared with $78 \%$ PT and $64 \% \mathrm{~T}$ in a study using direct interviews. ${ }^{16}$ For those who agreed to complete a questionnaire the response rate was high, although inevitably there must be some differences between those who returned one, and those who did not or were not traced. Table 1 suggests that although in terms of abilities at 12 years the groups were similar, more women and more PT replied. This in itself may not be too serious a problem as these groups have been considered separately in the analyses. Those returning questionnaires may have felt more motivated to do so because they had more problems, and indeed several contacts were made during the study by PT adults wanting to discuss educational and other difficulties. On the other hand returners may simply have been better educated and more used to completing forms. By the nature of the method used to select the cohort, those with major neurodisability were excluded as they did not attend mainstream schools. If they had been included, then the responses from the PT would have in all likelihood been poorer. In a similar study, exclusion of subjects with neurodisability made little difference to the conclusions, however. ${ }^{16}$ The cohort was also hospital based and selected on the basis of very low birth weight, increasing the proportion of growth restricted infants included. All efforts to trace the cohort by post were made, 
Table 7 Preferences and self-image

\begin{tabular}{|c|c|c|c|c|c|c|c|}
\hline \multirow{2}{*}{$\begin{array}{l}\text { Preference or } \\
\text { self-image }\end{array}$} & \multicolumn{3}{|l|}{ Male } & \multicolumn{3}{|l|}{ Female } & \multirow{2}{*}{$\begin{array}{l}\text { All } \\
\text { OR }(95 \% \mathrm{Cl})\end{array}$} \\
\hline & Preterm (35) & Term (30) & OR $(95 \% \mathrm{Cl})$ & Preterm (44) & Term (41) & OR $(95 \% \mathrm{Cl})$ & \\
\hline Taller & 15 & 11 & $1.30(0.48$ to 3.52$)$ & $27^{* *}$ & 13 & 3.4 (1.40 to 8.37$)$ & $2.2(1.15 \text { to } 4.31)^{*}$ \\
\hline Same & 20 & 17 & $1.02(0.38$ to 2.73$)$ & $15^{* *}$ & 27 & $0.27(0.11$ to 0.66$)$ & $0.48(0.25 \text { to } 0.94)^{*}$ \\
\hline Shorter & 0 & 2 & & 2 & 1 & 1.91 (0.17 to 21.84$)$ & $0.59(0.10$ to 3.63$)$ \\
\hline Heavier & 9 & 10 & $0.69(0.24$ to 2.02$)$ & 4 & 2 & $1.95(0.34$ to 11.26$)$ & $0.97(0.41$ to 2.29$)$ \\
\hline Same & 15 & 11 & $1.30(0.48$ to 3.52$)$ & 15 & 9 & $1.84(0.70$ to 4.84$)$ & $1.56(0.78$ to 3.11$)$ \\
\hline Lighter & 11 & 9 & 1.07 (0.37 to 3.08$)$ & 25 & 30 & $0.48(0.19$ to 1.20$)$ & $0.69(0.36$ to 1.31$)$ \\
\hline More attractive & 5 & 7 & 0.55 (0.15 to 1.95$)$ & $1^{* * *}$ & 13 & $0.05(0.01$ to 0.41$)$ & $0.21(0.08 \text { to } 0.56)^{\star * *}$ \\
\hline Average & 20 & 21 & $0.57(0.20$ to 1.60$)$ & 28 & 20 & $1.84(0.77$ to 4.37$)$ & $1.13(0.59$ to 2.18$)$ \\
\hline Less attractive & $10^{*}$ & 2 & $5.6(1.12$ to 28.05$)$ & 15 & 8 & $2.13(0.79$ to 5.76$)$ & $2.82(1.24 \text { to } 6.41)^{*}$ \\
\hline
\end{tabular}

Table 8 Membership of households, academic qualifications achieved, and employment status

\begin{tabular}{|c|c|c|c|c|c|c|c|c|c|}
\hline & \multicolumn{3}{|l|}{ Male } & \multicolumn{3}{|l|}{ Female } & \multicolumn{3}{|l|}{ All } \\
\hline & $\begin{array}{l}\text { Preterm } \\
\text { (35) }\end{array}$ & $\begin{array}{l}\text { Term } \\
(30)\end{array}$ & OR $(95 \% \mathrm{Cl})$ & $\begin{array}{l}\text { Preterm } \\
\text { (44) }\end{array}$ & $\begin{array}{l}\text { Term } \\
\text { (41) }\end{array}$ & OR $(95 \% \mathrm{Cl})$ & $\begin{array}{l}\text { Preterm } \\
\text { (79) }\end{array}$ & $\begin{array}{l}\text { Term } \\
\text { (71) }\end{array}$ & OR $(95 \% \mathrm{Cl})$ \\
\hline \multicolumn{10}{|c|}{ Members of household } \\
\hline Partner & 0 & 1 & & 2 & 4 & $0.44(0.08$ to 2.55$)$ & 2 & 5 & $0.34(0.06$ to 1.83$)$ \\
\hline Children & 0 & 0 & & 5 & 0 & & 5 & 0 & \\
\hline Parents & 32 & 23 & $3.25(0.76$ to 13.91$)$ & 33 & 23 & $2.34(0.94$ to 5.90$)$ & $65^{*}$ & 46 & $2.52(1.10$ to 5.37$)$ \\
\hline Siblings & 1 & 0 & & 0 & 1 & & 1 & 1 & $0.89(0.06$ to 14.61$)$ \\
\hline Others & 2 & 3 & 0.55 (0.09 to 3.50$)$ & $1^{\text {** }}$ & 13 & 0.05 (0.01 to 0.41$)$ & $3^{* * *}$ & 16 & 0.14 (0.04 to 0.49$)$ \\
\hline Alone & 0 & 3 & & 3 & 0 & & 3 & 3 & $0.89(0.18$ to 4.58$)$ \\
\hline \multicolumn{10}{|c|}{ Academic qualifications achieved } \\
\hline None & 1 & 1 & $0.85(0.05$ to 14.25$)$ & 3 & 0 & & 4 & 1 & $3.73(0.41$ to 34.21$)$ \\
\hline GCSE & 5 & 2 & $2.33(0.42$ to 13.02$)$ & 3 & 5 & $0.53(0.12$ to 2.36$)$ & 8 & 7 & $1.03(0.35$ to 3.00$)$ \\
\hline AS/A level & 2 & 3 & $0.55(0.09$ to 3.50$)$ & 4 & 3 & $1.27(0.27$ to 6.04$)$ & 6 & 6 & $0.89(0.27$ to 2.90$)$ \\
\hline NVQ/HND & $19^{*}$ & 7 & $3.9(1.3$ to 11.4$)$ & $24^{* *}$ & 9 & 4.27 (1.65 to 11.01$)$ & $43^{\star * *}$ & 16 & $4.11(2.01$ to 8.36$)$ \\
\hline Degree & $8^{*}$ & 17 & $0.23(0.08$ to 0.66$)$ & $10^{* *}$ & 24 & $0.20(0.08$ to 0.53$)$ & $18^{\star \star \star}$ & 41 & $0.21(0.11$ to 0.44$)$ \\
\hline \multicolumn{10}{|c|}{ Employment status } \\
\hline Paid work & 22 & 12 & $2.5(0.93$ to 6.91$)$ & 22 & 15 & 1.7 (0.73 to 4.13$)$ & $44^{*}$ & 27 & 2.01 (1.07 to 3.94 ) \\
\hline Unemployed & 5 & 1 & $4.83(0.53$ to 43.92$)$ & 1 & 0 & & 6 & 1 & $5.75(0.68$ to 49.00$)$ \\
\hline Training & 1 & 1 & $0.85(0.05$ to 14.25$)$ & 1 & 2 & $0.45(0.04$ to 5.20$)$ & 2 & 3 & $0.59(0.10$ to 3.63$)$ \\
\hline Disabled & 1 & 1 & $0.85(0.05$ to 14.25$)$ & 2 & 1 & $1.9(0.17$ to 21.84$)$ & 3 & 2 & $1.30(0.22$ to 8.39$)$ \\
\hline Student & $5^{\star *}$ & 14 & $0.19(0.06 \text { to } 0.63)^{* *}$ & $13^{*}$ & 22 & $0.36(0.15$ to 0.88$)$ & $18^{* \star *}$ & 36 & $0.28(0.14$ to 0.58$)$ \\
\hline Carer & 1 & 1 & $0.85(0.05$ to 14.25$)$ & 4 & 1 & $4.00(0.43$ to 37.38$)$ & 5 & 2 & $2.33(0.44$ to 12.40$)$ \\
\hline Other & 0 & 0 & & 1 & 0 & & 1 & 0 & \\
\hline
\end{tabular}

but many had moved house in the preceding 10 years. Attempts to trace new addresses for PT via general practitioners met with little response; this was not an option for the $\mathrm{T}$ controls as they had never been patients. It is hoped that the use of a unique patient identifier in the future and centralised databases will make tracing easier. Involvement in any research study is voluntary, and a number clearly declined by their actions.

In conclusion, despite its limitations, this study shows that adults born PT but without major disability have more physical health problems, but not more psychological problems than those born $\mathrm{T}$ in early adulthood. They appear to enjoy a wide range of social activities, although possibly engage in less risk taking behaviour. Their level of educational attainment is on average lower, but the great majority are in work or education, although there are more mothers at home and unemployed men. Further studies will be needed to ascertain whether this relatively optimistic picture is maintained in later adulthood.

\section{REFERENCES}

1 Cooke RWI. Annual audit of three year outcome in very low birth weight infants. Arch Dis Child 1993;69:295-8.
2 Bhutta AT, Cleves MA, Casey PH, et al. Cognitive and behavioural outcomes of school-aged children who were born preterm; a meta-analysis. JAMA 2002;288:728-37.

3 Botting N, Powls A, Cooke RWI, et al. Attention deficit hyperactivity disorders and other psychiatric outcomes in very low birth weight children at 12 years. J Child Psychol Psychiatry 1997;38:931-41.

4 Powls A, Botting N, Cooke RWI, et al. Growth impairment in very low birth weight children at 12 years: correlation with perinatal and outcome variables. Arch Dis Child Fetal Neonatal Ed 1996;75:F152-7.

5 Powls A, Botting N, Cooke RWI, et al. Motor impairment at 12-13 years in children with a birthweight of less than $1250 \mathrm{~g}$. Arch Dis Child Fetal Neonatal Ed 1995;73:F62-6.

6 Powls A, Botting N, Cooke RWI, et al. Handedness in very low birth weight children at 12 years of age: relation to perinatal and outcome variables. Dev Med Child Neurol 1996;38:594-602.

7 Marlow N, Roberts BL, Cooke RWI. Motor skills in extremely low birth weight children at the age of six years. Arch Dis Child 1989;64:839-47.

8 Powls A, Botting N, Cooke RWI, et al. Visual impairment in very low birth weight children. Arch Dis Child Fetal Neonatal Ed 1997;76:F82-7.

9 Botting N, Powls A, Cooke RWI, et al. Cognitive and educational outcome of very low birth weight children in early adolescence. Dev Med Child Neurol 1998;40:661-6.

10 Hess $\mathrm{JH}$. Experiences gained in a thirty year study of prematurely born infants. Pediatrics 1953;11:425-34.

11 Mazurier E, Lefebvre F, Tessier R. Educational achievement and intelligence at 16-21 years of ex-prematures born $<1000 \mathrm{~g}$ [abstract]. Pediatr Res 1999;45:250A.

12 Dessens AB, Smolders-de Hass H, Koppe JG. Twenty year follow-up of antenatal corticosteroid treatment [abstract]. Pediatrics 2000; 105: 1325. 
13 Bierager M, Steensberg J, Griesen G. Quality of life among young adults born with very low birth weights. Acta Paediatr 1995;84:1339-43.

14 Ericson A, Kallen B. Very low birthweight boys at age 19. Arch Dis Child Fetal Neonatal Ed 1998:78:F171-4.

15 Xu B, Rantakallio P, Jarvelin M-R. Mortality and hospitalizations of 24-yearold members of the low-birthweight cohort in northern Finland. Epidemiology 1998;9:662-5

16 Hack M, Flannery DJ, Schluchter $M$, et al. Outcomes in young adulthood for very-low-birth-weight infants. N Engl J Med 2002;346:149-57.

17 Wolke D, Sohne B, Ohrt B, et al. Follow-up of preterm children; important to document dropouts. Lancet 1995;345:447.
18 Aylward GP, Hatcher RP, Stripp B, et al. Who goes and who stays; subject loss in a multicenter, longitudinal follow-up study. J Dev Behav Pediatr 1985;6:3-8

19 Ware JE, Snow KK, Kosinski M, et al. SF-36 Health Survey: manual and interpretation guide. Boston, MA: The Health Institute, New England Medical Center, 1993.

20 Zigmond AS, Snaith RP. The Hospital Anxiety and Depression Scale. Acta Psychiatr Scand 1983:67:361-70.

21 Jenkinson C, Coulter A, Wright L. Short Form-36 (SF-36) health survey questionnaire: normative data for adults of working age. $B M$ 1993;306: 1437-40.

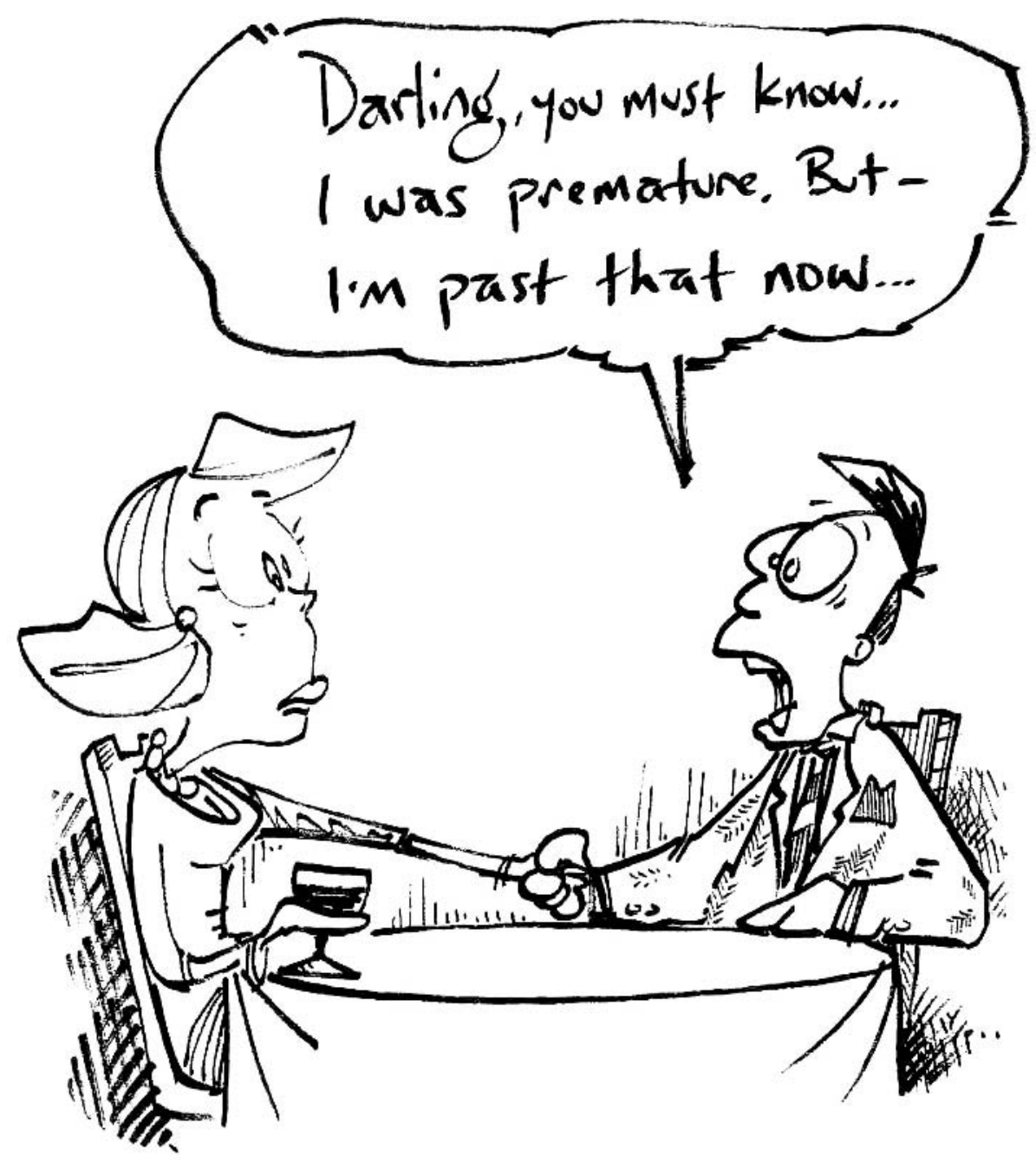

